\title{
Feasibility Studies and Important Aspect of Project Management
}

\author{
Momin Mukherjee and Sahadev Roy
}

\begin{abstract}
In this paper we want to describe stepwise, different studies are essential for design and layout of plants. In this paper we also described different benefit conducting the feasibility studies. The survey is also extended more detailed regarding different considerations. Here we also discussed different test parameters. We also try to measures different impact on the organizational characteristics; fulfil user requirements. Five essential areas of project feasibility are also discussed here. Benefits of conducting feasibility study and different aspects consider here for discussion.
\end{abstract}

\section{Keywords}

Design and layouts of plants;

Feasibility study;

Legal feasibility;

Operational feasibility;

Scheduling feasibility;

Technical feasibility.

\section{INTRODUCTION}

The feasibility study is procedure to predict outcome of an investigation examination, or assessment of a planned scheme along with possible gain [1]. These studies allow proper investigating and evaluating any production a plane or business prospect and also on the essential requirement to commence the project [2]. A feasibility studies are important and essential to evolutes the any proposed project is feasible or not [3]. There are two main motivations regarding this are location assessment of the desire project and cost expectation [4]. A proper planes is one of the essential criteria for propose sequential operation and environment to deliver any products or services [5]. The organization accounting declaration, information management procedure, proper advertising, different economic condition, local and international laws etc. considerations are mandatory. The necessities and different excise responsibility also consider under the feasibility studies [6]. Usually, these studies appeared first in terms of technological development and implementation. A proper feasibility study is essential for probable achievement [7]. This study also helps the project manager to see viability of the particular idea which gives the fruitful deliverable from the project within optimal cost, time, resources and also justifying the factors like legal, technical \& economical [8]. The purpose of the feasibility study is not to provide exact solution of any problem related to the design and layout of plant but to provide a sense of its desire scopes [9]. During the study of the scope different aspects of the organization and its implementation costs and desire benefits are estimate with proper accuracy.

\section{Areas of Project feasibility}

In this section we discuss different area of the project feasibility which may be consider during the assessment of any project. For every project transient and also in development phase the feasibility may consider as an important steps for the investor or the organization to make sure that their mission is officially feasible, gainful for the organization and beneficial for society. The methodical study may also provide the exact respond earlier. Feasibility evaluation mainly classify in five types or categories.

\section{A. Technical Feasibility}

Technical feasibility mainly associated with the technologically evolutes the project. In this subject area generally a group of engineers or technical expert study the whole projects and technical aspects. This study facilitates said organizations to proper assess. The industrial possessions may assemble capability. Based on the results it decides whether the technical team is able to convert the idea into real [10].

\section{B. Economic Feasibility}

Economic feasibility study related with price, and all kind of expenditure related with the scheme before the project start. This study also improves project reliability [11]. It is also helpful for the decision-makers to decide the planned scheme processed latter or now, depending financial condition of the organization [12]. This evaluation process also studies the price benefits of the proposed scheme.

\section{Legal Feasibility}

Legal feasibility study is use to conclude whether the proposed plan or system is conflicts with the national or international legal requirements [13]. Protection Acts simply use to decide the any violation the legal requirements. It is also a planned method [14].

\section{Operational Feasibility}

Operational Feasibility may employ the responsibility to examine and also decide whether the proposed methods fulfil all kind of business requirements [15]. It actions forecast all possible schemes to recognized and resolves troubles [16]. This studies may also examine and verify how the project planed guarantee the method development is feasible or not.

\section{E. Scheduling Feasibility}

A very significant part of feasibility study is scheduling Feasibility. It is also play an important roles to complete the project in its schedule time [17]. A 
project some time not be unsuccessful if it is not finished in its bounded time frame [18]. Here we may predict the time requirement to complete various task of the entire project [19].

\section{ELEMENTS OF A GOOD FEASIBILITY StUdY}

In successful business feasibility study of projects is a critical factor. Sometimes we noticed that a number of projects be unsuccessful because of their incorrect facts or incorrect assumptions. Therefore, the basic features in any feasibility study must be ensuring that we are working with accurate information, exact statement, and the latest financial records [20]. The main objective of feasibility study is to evaluate three types of feasibility; technical, operational and economic feasibility. In this stage, only the project cost of the development and implementation cost of the project is considered.

Feasibility study may also depend on the numerous factors, like the risks of the project before and after project and potential returns of the investments.

- Over all expendature and the funds, availablality of the fund.

- Priorities of the other busness and running projects of the realted firm.

- $\quad$ Target users.

It is in simply verify the changes before the project design. Importance of performing a Feasibility Study

Some major benefits of conducting a feasibility study are the following. Conduct a feasibility study is always important because of it gives a clear idea of the dreamed project [21]. It helps to identify the valid and proper reason to select the project. With the support of feasibility study project teams members become more focused. It helps to decision-making on the project. Improve the achievement time by calculating several restrictions.

It focuses on few general criteria:

(i) The user's demonstrable requirements and how the proposed system meet them?

(ii) What are possible resources are available and the present project utilized these resoureces?

(iii) Likely impact of the proposed system on the organization and it is really fit with the organization.

The proper investigation and evaluation procedure of the proposed project is mainly identification of the possible problem, specification, expected performance and also the cost of each sub-system and selection of the best and efficient procedures.

The outcome of the study is generally consider as formal proposal of the expected system. This is basically a report about the scope of the projected solution. The proposals are summarizes with the expected so. It consists of the following:

1. Brief statement of the proposed project - a carefully worded and may be the graphical statement of the proposed problem.

2. Summary of the outcome - a list of the major outcome from the study.
3. Details of findings- an outline of the proposed methods and procedures of the desired plan undertaken to complete task with all possible finding. This report also included the possible structures, costs estimation and benefits of the desire projects.

4. Recommendations and final conclusions- Few specific advice and recommendations based on its outcome along with the personnel assignments, projected costs and target dates.

Basically it is a predictable project that demonstrate conclusion of the assessment, examine and evaluation of a designed method and terminate if this method is accurately feasible, profitable and productive.

\section{Conclusion}

Careful reviews of any proposal are essential before its design and development phase. The formal agreement may lead the process for actual implementations of the process. It may be a crucial and many projects may be incomplete due to lack of feasibility study in its implementation phase. Changes in the proposal after inciting the process may be leading the project die. Depending on the initial investigation result, the survey may be extended feasibility study. The feasibility study is a systematic proposal depending work characteristics. This study also measures the impact on the business organization, help to meet user demands, and proper utilization of resources.

\section{REFERENCES}

[1] Krieger, T., Martig, D. S., van den Brink, E., \& Berger, T. (2016). Working on self-compassion online: A proof of concept and feasibility study. Internet Interventions, 6, 64-70.

[2] Liaquat, A. M., Kalam, M. A., Masjuki, H. H., \& Jayed, M. H. (2010). Potential emissions reduction in road transport sector using biofuel in developing countries. Atmospheric Environment, 44(32), 38693877.

[3] Mintzberg, H., Raisinghani, D., \& Theoret, A. (1976). The structure of" unstructured" decision processes. Administrative science quarterly, 246275.

[4] Langmyhr, T. (1999). Understanding innovation: the case of road pricing. Transport Reviews, 19(3), 255-271.

[5] Mukherjee, K. (2016). The Psychology of the Successful Entrepreneur. International Journal of Advanced Engineering and Management, 1(1), 2532.

[6] Current, J., Min, H., \& Schilling, D. (1990). 
Multiobjective analysis of facility location decisions. European Journal of Operational Research, 49(3), 295-307.

[7] Dvir, D., Lipovetsky, S., Shenhar, A., \& Tishler, A. (1998). In search of project classification: a nonuniversal approach to project success factors. Research policy, 27(9), 915-935.

[8] Khan, A. (2006). Project scope management. Cost engineering, 48(6), 12-16.

[9] Shen, L. Y., Tam, V. W., Tam, L., \& Ji, Y. B. (2010). Project feasibility study: the key to successful implementation of sustainable and socially responsible construction management practice. Journal of Cleaner Production, 18(3), 254259.

[10] Schwender, J. D., Holly, L. T., Rouben, D. P., \& Foley, K. T. (2005). Minimally invasive transforaminal lumbar interbody fusion (TLIF): technical feasibility and initial results. Clinical Spine Surgery, 18, S1-S6.

[11] Bridgwater, A. V. (1995). The technical and economic feasibility of biomass gasification for power generation. Fuel, 74(5), 631-653.

[12] Mukherjee, M. (2017). Entrepreneurial Judgment and Analysis for Successful Strategy Implementation. International Journal of Advanced Engineering and Management, 2(1),1-8.

[13] Abdollahbeigi, B., Salehi, F., \& Jayashree, S. (2017). The Effect of Recruitment, Selection and Development on Talent Management in IKCO Company in Iran. 2(3), 69-77.

[14] Brodley, J. F. (1975). Industrial Deconcentration and Legal Feasibility: The Efficiencies Defense. Journal of Economic Issues, 9(2), 365380.

[15] Pollock, J., Ho, S. V., \& Farid, S. S. (2013).
Fed-batch and perfusion culture processes: Economic, environmental, and operational feasibility under uncertainty. Biotechnology and bioengineering, 110(1), 206-219.

[16] Roy, A., \& Mukherjee, K. (2017). Entrepreneurial Education in India. International Journal of Advanced Engineering and Management, 2(1), 1520.

[17] Aiken, L. H., Sochalski, J., \& Lake, E. T. (1997). Studying outcomes of organizational change in health services. Medical care, 35(11), NS6-NS18.

[18] Dobson, G. (1987). The economic lot-scheduling problem: achieving feasibility using time-varying lot sizes. Operations research, 35(5), 764-771.

[19] Boje, D. M. (1991). The storytelling organization: A study of story performance in an office-supply firm. Administrative science quarterly, 106-126.

[20] Adams, J., Khan, H. T., Raeside, R., \& White, D. I. (2007). Research methods for graduate business and social science students. SAGE publications India.

[21] Mukherjee, M. (2017). Innovation and System Design.International Journal of Advanced Engineering and Management,2(2), 29-32.

Authors Details:

Momin Mukherjee

Dept. of Management and Humanatics, NIT Arunachal Pradesh, India

Email: mmukherjee964@gmail.com

Sahadev Roy

Dept. of ECE, NIT Arunachal Pradesh, India

Email: sahadevroy@gmail.com 